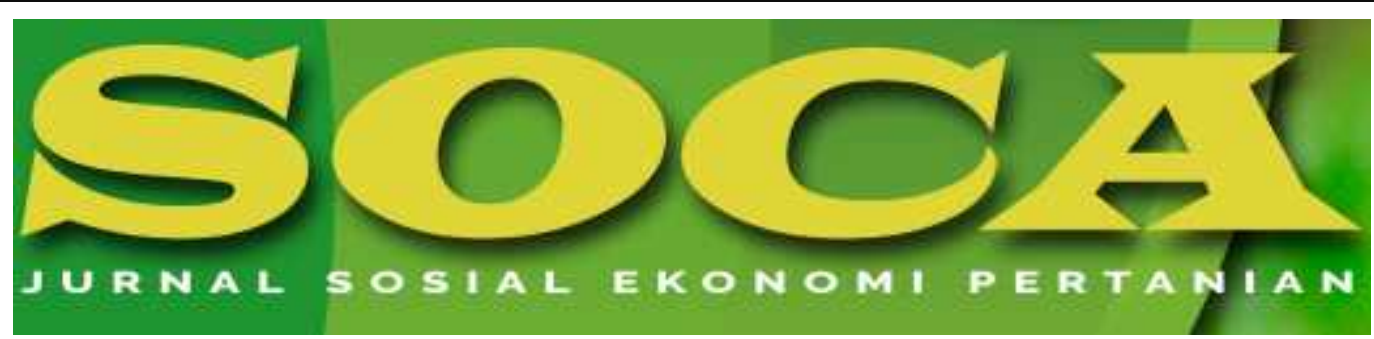

https://ojs.unud.ac.id/index.php/soca

\title{
VALUASI EKONOMI OBJEK WISATA HUTAN MANGROVE MUNJANG DI DESA KURAU BARAT KABUPATEN BANGKA TENGAH
}

\author{
Soleha, Yudi Sapta Pranoto dan Evahelda \\ Universitas Bangka Belitung, Kota Pangkalpinang, Provinsi Kep. Bangka Belitung \\ Email Korespondensi: solehabakri@gmail.com, udhei_sapta@yahoo.co.id \\ evaheldaubb@gmail.com, \\ Telepon/Hp: 082176869992, 085267143455, 081367707791
}

\begin{tabular}{l}
\hline Kata Kunci: \\
Valuasi, \\
Mangrove, \\
Biaya \\
Perjalanan \\
\hline
\end{tabular}

\begin{abstract}
Abstrak
Penelitian ini bertujuan untuk menghitung nilai ekonomi berdasarkan biaya perjalanan (travel cost) dan jasa lingkungan objek wisata Hutan Mangrove Munjang. Penelitian ini dilakukan di kawasan Hutan Mangrove Munjang di Desa Kurau Barat Kecamatan Koba Kabupaten Bangka Tengah dimulai bulan November 2018 sampai Juni 2019. Metode penelitian yang digunakan adalah metode survei. Metode penarikan contoh menggunakan teknik accidental sampling untuk penentuan responden pengunjung tempat wisata yaitu sebanyak 100 responden yang diperoleh menggunakan rumus Rao Purba, serta metode analisis biaya perjalanan menggunakan analisis Korelasi Person. Hasil penelitian menunjukan secara keseluruhan nilai ekonomi Hutan Mangrove Munjang adalah sebesar Rp28.292.560.968 per tahun yaitu nilai flora Rp15.037.827.000, nilai fauna Rp7.286.730.000, nilai serapan karbondioksida Rp4.261.243.068 dan nilai biaya perjalanan sebesar Rp1.706.760.900. Hasil korelasi antara biaya perjalanan dengan jumlah kunjungan menunjukkan hubungan yang kuat yaitu -,540 dengan arah hubungan negatif yaitu semakin tinggi biaya perjalanan yang dikeluarkan pengunjung maka semakin rendah keinginan pengunjung untuk melakukan perjalanan ke tempat wisata begitu pula sebaliknya.
\end{abstract}


EKONOMIC VALUATION OF TOURISM OBJECTS OF MANGROVE MUNJANG FOREST IN THE VILLAGE OF KURAU BARAT CENTRAL BANGKA REGENCY

\begin{tabular}{l}
\hline Keywords: \\
valuation, \\
Mangrove, cost \\
of tour \\
\hline
\end{tabular}

How to Cite (APA 6th Style):

Soleha, Pranoto, Y. S., \& Evahelda. (2020). Valuasi Ekonomi Objek Wisata Hutan Mangrove Munjang Di Desa Kurau Barat Kabupaten Bangka Tengah. SOCA: Jurnal Sosial Ekonomi Pertanian, 14(1), 101-113. https://doi.org/https://doi.org/ 10.24843/SOCA.2020.v14.i01.p09

\section{PENDAHULUAN}

Sebagai salah sau ekosistem pesisir, hutan mangrove merupakan ekosistem yang unik. Ekosistem ini mempunyai fungsi ekologis dan ekonomis. Fungsi ekologis hutan mangrove antara lain mencegah abrasi, habitat dan tempat pembesaran serta tempat pemijahan bagi aneka biota perairan. Sedangkan fungsi ekonominya antara lain sebagai penghasil keperluan rumah tangga, keperluan industry serta sebagai tempat wisata (Aco, 2015).

Mangrove merupakan salah satu ekosistem langka, karena luasnya pada Tahun 2015 hanya 16.530.000 hektar. Berdasarkan data yang dikemukakan oleh Direktur Bina Pengelolaan Kawasan Ekosistem Esensial pada siaran Pers di Gedung Manggala Wanabakti Jakarta Tahun 2017, bahwa Indonesia memiliki kawasan ekosistem mangrove terluas yaitu 23 persen dari luas mangrove di Dunia atau seluas 3.489.140,68 hektar. Provinsi Kepulauan Bangka Belitung memiliki potensi hutan mangrove seluas $273.692,81$ hektar. Salah satu daerah yang memiliki potensi alam hutan mangrove yaitu Desa Kurau Barat yang berada di Kecamatan Koba, Kabupaten Bangka Tengah yang memiliki luas lahan 6,52 km² (BPS, 2017). 
Hutan mangrove di Desa Kurau Barat merupakan hutan lindung yang telah memiliki status sebagai Hutan Kemasyarakatan $(\mathrm{HKm})$ pada ahun 2015 oleh kementerian lingkungan hidup dan kehutanan (KLHK). Keberadaan hutan mangrove sangat penting guna menghindari pengikisan yang terjadi akibat air laut, menahan ombak yang tinggi serta menghalangi tiupan angina yang kencang dari laut menuju ke darat. Hutan mangrove di Desa Kurau Barat memiliki luas 213 hektar yang dikelola oleh suatu organisasi yaitu Generasi Muda Pencinta Alam 01 (GEMPA 01).

Pada tanggal 27 Juni 2017 hutan mangrove telah diresmikan sebagai Ekowisata Mangrove Munjang oleh Gubernur Provinsi Kepulauan Bangka Belitung. Ekowisata mangrove merupakan objek wisata yang berwawasan lingkungan dimana wisata tersebut mengutamakan aspek keindahan yang alami dari hutan mangrove serta fauna yang hidup disekitarnya tanpa harus merusak ekosistem tersebut untuk membuatnya lebih menarik wisatawan, hal ini disebabkan karena hutan mangrove memiliki banyak flora dan fauna yang hidup di dalamnya. Pemanfaatan ekosistem mangrove sebagai ekowisata harus direncanakan dengan baik seperti upaya dalam mempertahankan keaslian komponen biologi dan fisik yang menjadi daya tarik utama kegiatan ekowisata mangrove. Nilai estetika, keunikan, pendidikan, serta potensi keanekaragaman hayati menjadi alasan utama layaknya hutan mangrove dijadikan sebagai tempat ekowisata.

Menurut Ghuffran dan Kordi (2012), keberadaan kawasan vegetasi mangrove di daerah pasang surut yang lingkungannya mendukung kegiatan perikanan menyebabkan kawasan ini banyak dimanfaatkan untuk usaha pertambakan dan perluasan lahan permukiman dengan mengorbankan vegetasi mangrove yang menyebabkan degradasi hutan mangrove menjadi sangat tinggi mengingat mangrove memiliki tiga fungsi utama yaitu fungsi fisik yang meliputi pencegah abrasi, perlindungan terhadap angin dan ombak, serta penyerapan karbon. Fungsi biologis yang meliputi tempat bertelur dan asuhan biota, tempat bersarang burung, maupun habitat biota laut lainnya, serta fungsi ekonomi (Prasetiyo, 2013).

Penelitian ini bertujuan untuk Menghitung nilai ekonomi objek wisata Hutan Mangrove Munjang di Desa Kurau Barat Kabupaten Bangka Tengah dilihat dari biaya perjalanan (travel cost) dan jasa lingkungannya.

\section{METODE PENELITIAN}

Penelitian ini dilakukan di Desa Kurau Barat, Kecamatan Koba, Kabupaten Bangka Tengah mulai bulan November 2018 sampai bulan Juni 2019. Lokasi penelitian ditenukan secara sengaja dengan pertimbangan bahwa lokasi tersebut merupakan salah satu lokasi pariwisata yang telah diresmikan menjadi ekowisata hutan mangrove oleh Gubernur Bangka Belitung pada Tahun 2017.

Metode dalam penelitian ini menggunakan metode survei. Menurut Umar (2011), metode survei merupakan suatu kegiatan pengambilan data secara langsung ke lapangan dengan cara mengambil contoh untuk mengetahui hubungan antara variabel yang ditentukan dalam penelitian. Metode penarikan contoh menggunakan teknik accidental sampling atau pengambilan sampel secara kebetulan, yaitu siapa saja yang secara kebetulan yang bertemu dengan peneliti bisa dijadikan sampel bila dipandang orang yang kebetulan ditemui itu cocok sebagai sumber data (Sugiyono, 2009). Untuk penentuan responden pengunjung tempat wisata yaitu sebanyak 100 responden menggunakan rumus Rao Purba dalam Setiawan (2017) berikut: 


$$
N=\frac{Z^{2}}{4(M)^{2}}
$$

Keterangan:

$\mathrm{N} \quad$ : Jumlah sampel

Z : Tingkat distribusi normal pada taraf signifikansi 5\% $=1,96$

Moe : Margin of error atau kesalahan maksimal yang bisa dikolerasi, di sini ditetapkan 10 persen atau 0,10.

Dengan menggunakan margin of error sebesar 10\%, maka jumlah sampel minimal yang dapat diambil sebesar.

$$
N=\frac{1,9^{2}}{4(\mathrm{U}, 1)^{2}}=96,04 \text { dibulatkan menjadi } 96 \text { responden }
$$

Berdasarkan penghitungan di atas, maka sampel yang digunakan dalam penelitian ini berjumlah 96 responden, tetapi untuk lebih memudahkan dalam penarikan kesimpulan peneliti akan mengambil sampel sebanyak 100 responden untuk mewakili angka 100 persen.

Metode pengumpulan data menggunakan metode observasi, wawancara, kuisioner, studi pustaka dan dokumentasi. Metode pengolahan dan analisis data menggunakan metode biaya perjalanan, jasa lingkungan dan nilai ekonomi total (NET) dengan penjelasan sebagai berikut:

\section{Metode Pengolahan Data Nilai Ekonomi Berdasarkan Biaya Perjalanan (Travel Cost)}

Untuk menghitung nilai ekonomi objek wisata Hutan Mangrove Munjang yaitu dengan menghitung biaya perjalanan rata-rata dari masing-masing zona dengan cara menjumlahkan biaya transportasi, konsumsi yaitu biaya makan dan minum, parkir, serta biaya masuk yang dikeluarkan selama melakukan kegiatan wisata. Selanjutnya dibagi dengan total responden yang berada dalam kelompok zona tersebut. Rumusnya yaitu sebagai berikut:

$$
B=\frac{B+B+\cdots+B p i 1}{n}
$$

Keterangan:

$\mathrm{BP}=$ Biaya perjalanan rata-rata masing-masing zona

$\mathrm{Bpi} \quad=(\mathrm{BT}+\mathrm{BK}+\mathrm{BP}+\mathrm{BSP})$

Bpin = Biaya perjalanan individu ke-n masing-masing zona

BT = Biaya Transportasi

$\mathrm{BK} \quad=$ Biaya Konsumsi

$\mathrm{BP} \quad=$ Biaya Parkir

$\mathrm{BSP}=$ Biaya Sewa Perahu

Mendapatkan jumlah kunjungan (Y) tiap 1.000 per tahun dilakukan dengan cara sebagai berikut:

1. Mencari data jumlah kunjungan per tahun

2. Mengelompokkan pengguna wisata Hutan Mangrove Munjang sesuai dengan alamat 
3. Menentukan jumlah kunjungan tiap 1.000 penduduk per tahun dengan rumus umum:

$$
\text { Kunjungan } / 1.000 / \text { tahun }=\frac{\left(\frac{v}{n}\right) N 1}{p}
$$

Keterangan:

vi = Jumlah kunjungan dari zona $\mathrm{i}$

$\mathrm{n} \quad=$ Jumlah sampel

$\mathrm{N} \quad=$ Jumlah pengunjung per tahun

pi $\quad=$ Jumlah penduduk total di zona $\mathrm{i}$

\section{Metode Regresi Nilai Ekonomi Objek Wisata Hutan Mangrove Munjang}

Menurut Supranto 2001 dalam Suhandar (2016), regresi sederhana adalah memperkirakan hubungan dua variabel ttanpa membuat asumsi terlebih dahulu mengenai bentuk hubungan yang dinyatakan dalam fungsi tertentu. Dalam penelitian kali ini tahap-tahap melakukan regresi sederhana dapat dilihat sebagai berikut:

1) Melakukan regresi sederhana variabel independen dan biaya perjalanan sebagai variabel dependen. Rumus umum regresi sederhana yaitu:

$$
Y=\alpha+\beta
$$

Keterangan:

$\mathrm{Y}=$ Jumlah kunjungan per tahun

$\mathrm{X}=$ Biaya perjalanan

2) Menginvestasikan persamaan fungsi asal $\mathrm{X}$ menjadi fariabel tak bebas $\mathrm{Y}$ sebagai variabel bebasnya dengan rumus:

$$
\mathrm{X}=\frac{\alpha-\gamma}{\beta}
$$

3) Memperkirakan kesediaan membayar rata-rata tiap 1.000 penduduk per tahun dengan menggunakan persamaan matematika sebagai berikut:

$$
U=\int_{b}^{a} f(Y) \tilde{\mathrm{y}}
$$

Keterangan:

$\mathrm{U} \quad=$ Utiliti (kesediaan membayar)

$\int_{b}^{a} f \quad=$ fungsi integral

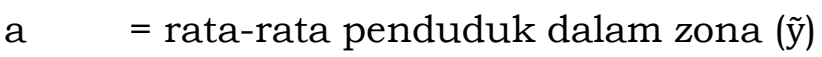

$\mathrm{b} \quad=\mathrm{X}(0)$

4) Memperkirakan biaya perjalanan rata-rata $X$ tiap 1.000 penduduk per tahun dilakukan dengan mengalikan hasil langkah dua dengan ỹ (rerata jumlah kunjungan tiap 1.000 penduduk per tahun.

5) Memperkirakan jumlah rata-rata yang dibayar tiap 1.000 penduduk per tahun dari zona yang dilakukan dengan mengalikan hasil langkah empat dengan ỹ.

6) Memperkirakan surplus konsumen dengan cara mengurangi hasil langkah tiga dengan hasil langkah lima. 
7) Memperkirakan Total Nilai Ekonomi (TNE) dilakukan dengan menggunakan rumus:

$$
\begin{array}{lrrr}
N \quad R \quad-r & x / u & h P \\
1.000
\end{array}
$$

Keterangan:

Nilai rata-rata = Kesediaan membayar $(\mathrm{KM})$, nilai yang dibayar (NA), dan surplus konsumen (SK)

Jumlah Penduduk = Dihitung berdasarkan zona $\mathrm{i}$

Setelah melakukan perhitungan regresi sederhana maka untuk menghitung nilai korelasi dijelaskan sebagai berikut:

- Jika nilai koefisien korelasi mendekati 1 atau -1 maka hubungan antara variabel $\mathrm{X}$ (independen) dengan variabel Y(dependen) erat atau kuat, sedangkan jika koefisien semakin mendekai 0 maka hubungan antara variabel $\mathrm{X}$ dengan variabel Y lemah.

- Sedangkan untuk menyatakan arah hubungan antara variabel $\mathrm{X}$ dengan variabel Y maka dilihat dari nilai koefisien korelasi dimana jika nilai koefisien korelasi (T) $>0$ maka terdapat hubungan posiif antara variabel $\mathrm{X}$ dengan variabel $\mathrm{Y}$, artinya semakin besar nilai variabel $\mathrm{X}$ maka semakin besar pula nilai variabel $\mathrm{Y}$ dan sebaliknya semakin kecil nilai variabel X maka semakin kecil pula nilai variabel Y. sedangkan jika nilai koefisien korelasi $(\mathrm{T})<0$ maka terdapat hubungan negatif antara variabel $\mathrm{X}$ dengan variabel $\mathrm{Y}$, artinya semakin kecil nilai variabel $\mathrm{X}$ maka semakin besar nilai variabel $\mathrm{Y}$ dan sebaliknya semakin besar nilai variabel $\mathrm{X}$ maka semakin kecil nilai variabel Y.

\section{Metode Pengolahan Data Nilai Ekonomi Berdasarkan Jasa Lingkungan}

Pengolahan data hasil penelitian untuk perhitungan nilai ekonomi flora, fauna, dan nilai ekonomi serapan karbon berdasarkan panduan valuasi ekonomi ekosistem hutan peraturan Menteri Negara Lingkungan Hidup Republik Indonesia Nomor 5 Tahun 2012.

1) Nilai Ekonomi Flora dan Fauna

Dalam penelitian ini, untuk menghitung nilai ekonomi flora dan fauna yaitu data jumlah flora dan fauna diambil berdasarkan hasil pengamatan dan data dari pengurus hutan mangrove di Desa Kurau Barat dengan harga yang ditetapkan berdasarkan asumsi harga pasar. Adapun harga perhitungan nilai ekonomi flora dan fauna yaitu:

Nilai Ekonomi Flora:

Nilai Ekonomi Flora = Jumlah Flora x Harga Flora

Nilai Ekonomi Fauna:

Nilai Ekonomi Fauna = Jumlah Fauna x Harga Fauna 
2) Metode Perhitungan Nilai Penyerapan Karbon

Menghitung nilai ekonomi penyerapan karbon di objek wisata hutan mangrove berdasarkan perhitungan nilai penyerapan karbon dengan menentukan harga jual karbon di pasar internasional serta kandungan karbon setiap jenis hutan. Menurut data dari World Bank (2004) dalam Karmila (2015), harga karbon yaitu sebesar 10\$ USD. Sedangkan harga dollar sekarang 1\$ diasumsikan Rp14.138,40.

\section{HASIL DAN PEMBAHASAN}

\section{Valuasi Ekonomi Objek Wisata Hutan Mangrove Munjang Berdasarkan Biaya Perjalanan (Travel Cost)}

Menurut Noya (2012), valuasi ekonomi merupakan salah satu cara yang dilakukan untuk memberikan nilai kuantitatif terhadap barang dan jasa yang dihasilkan sumberdaya alam dan lingkungan, baik dari nilai pasar (market value) atau non pasar (non market value). Metode biaya perjalanan (travel cost) berguna untuk menemukan nilai wisata alam yang menyediakan berbagai kesenangan untuk rekreasi, serta daerah-daerah yang sering kali dikunjungi oleh orang-orang untuk kegiatan seperti darmawisata. Nilai ekonomi rekreasi dengan menggunakan metode biaya perjalanan meliputi biaya transportasi pulang pergi dari tempat tinggalnya ke objek wisata dan pengeluaran lain selama di perjalanan dan di dalam objek wisata mencakup konsumsi, parkir, dan biaya lain (Susilowati, 2009).

Perhitungan untuk nilai ekonomi wisata dilakukan dengan perhitungan biaya perjalanan dengan melihat jumlah responden (JR), jumlah pengunjung (JP), jumlah pengunjung tempat wisata tahun (JPTWT) 2018, biaya perjalanan rata-rata (BPR), dan jumlah kunjungan per 1.000 penduduk (JKP1.000P) yang disajikan pada Tabel 1 .

Table 1. Jumlah Kunjungan Per 1.000 Penduduk Per Tahun 2019

\begin{tabular}{lccccc}
\hline \multicolumn{1}{c}{ Zona } & JR & $\begin{array}{c}\text { JP } \\
\text { (orang) }\end{array}$ & $\begin{array}{c}\text { JPTWT } \\
2018\end{array}$ & $\begin{array}{c}\text { BPR } \\
\text { (orang) }\end{array}$ & $\begin{array}{c}\text { JKP } \\
\text { (orang) } \\
\text { (orang }\end{array}$ \\
\hline Bangka Tengah & 23 & 192.429 & 12.000 & 53.870 & 14,343 \\
Bangka Selatan & 25 & 205.901 & 12.000 & 73.400 & 14,570 \\
Pangkalpinang & 28 & 208.520 & 12.000 & 71.964 & 16,113 \\
Bangka Induk & 20 & 330.793 & 12.000 & 92.450 & 7,255 \\
Bangka Barat & 4 & 209.011 & 12.000 & 119.500 & 2,296 \\
\hline Jumlah & 100 & 1.146 .654 & 60.000 & 411.184 & 54,577 \\
\hline Rata-rata & 20 & $229.330,8$ & 12.000 & $82.236,8$ & 10,915
\end{tabular}

Sumber: Olahan Data Primer 2019

Untuk menghitung nilai ekonomi objek wisata Hutan Mangrove Munjang maka dapat dilakukan perhitungan dengan menggunakan regresi sederhana yang perhitungan untuk nilai persamaan $\mathrm{Y}=\alpha+\beta$ dimana $\mathrm{Y}$ merupakan jumlah kunjungan per 1.000 penduduk, dan X merupakan biaya perjalanan rata-rata.

Dari hasil perhitungan pertama sampai terakhir didapatkanlah hasil untuk menghitung nilai ekonomi objek wisata Hutan Mangrove Munjang, yang dihitung 
berdasarkan surplus konsumennya yang dimana rumus perhitungannya sebagai berikut:

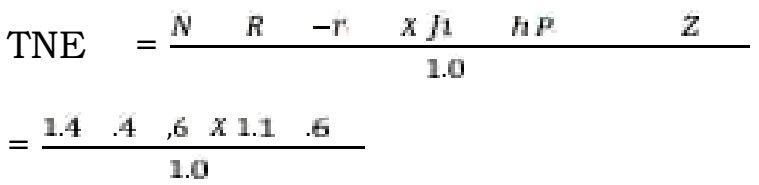

$=1.706 .760 .900$

Jadi, total ekonomi objek wisata Hutan Mangrove Munjang yang dihitung dengan menggunakan metode biaya perjalanan diperkirakan sebesar Rp1.706.760.900 per tahunnya.

\section{Analisis Korelasi Antara Biaya Perjalanan Dengan Jumlah Kunjungan}

Hubungan antara biaya perjalanan (X) dengan jumlah pengunjung (Y) di tempat wisata Hutan Mangrove Munjang yaitu dengan menggunakan korelasi person disajikan pada Tabel 2 berikut.

Tabel 2. Hasil Korelasi antara Biaya Perjalanan dan Jumlah Kunjungan Tahun 2019

\begin{tabular}{llcc}
\hline & Pearson Correlation & $\begin{array}{c}\text { Biaya } \\
\text { Perjalanan }\end{array}$ & $\begin{array}{c}\text { Jumlah } \\
\text { Kunjungan }\end{array}$ \\
\hline Biaya Perjalanan & Sig. (2-tailed) & 1 &,$- 540^{* *}$ \\
& $\mathrm{~N}$ & 100 &, 000 \\
Jumlah Kunjungan & Pearson Correlation &,$- 540^{* *}$ & 100 \\
& Sig. (2-tailed) &, 000 & 1 \\
& $\mathrm{~N}$ & 100 & 100 \\
\hline
\end{tabular}

Sumber: Olahan Data Primer, 2019

Hasil analisis korelasi berdasarkan nilai signifikansi, dari output diatas diketahui antara biaya perjalanan (X) dengan jumlah kunjungan (Y) nilai signifikansi yaitu 0,000 dengan taraf kepercayaan 0,01 yang berarti variabel $\mathrm{Y}$ dan variabel $\mathrm{X}$ memiliki tingkat kepercayaan sebesar 99 persen. Koefisien korelasi person antara variabel X dan variabel Y menunjukkan nilai -0.540. Berkenaan nilai koefisien mendekati 1 atau -1 maka hubungan antara variabel $\mathrm{Y}$ dan $\mathrm{X}$ erat atau kuat, jadi taraf toleransi 0,01 menunjukkan toleransi yang kuat. Sejalan dengan penelitian Sarwono (2012), yang mengatakan jika arah hubungan variabel $\mathrm{X}$ dan variabel $\mathrm{Y}$ mendekati -1, artinya semakin tinggi biaya perjalanan yang dikeluarkan pengunjung maka semakin rendah keinginan pengunjung untuk melakukan perjalanan ke tempat wisata begitu pula sebaliknya, semakin rendah biaya perjalanan yang dikeluarkan pengunjung maka semakin tinggi keinginan pengunjung untuk melakukan perjalanan ke tempat wisata. 


\section{Valuasi Ekonomi Objek Wisata Hutan Mangrove Munjang Berdasarkan Jasa Lingkungan}

Menurut Karmila (2015), jasa lingkungan merupakan fungsi ekosistem, baik yang masih bersifat alami maupun buatan yang memberi manfaat langsung atau tidak langsung dalam peningkatan kualitas lingkungan untuk kesejahteraan masyarakat. Hal ini sejalan dengan penelitian Suhandar (2016) yang menyebutkan bahwa jasa lingkungan hutan mangrove merupakan produk alami dari keseluruhan kawasan hutan berupa keindahan panorama alam, udara bersih dan segar, serta keindahan biota yang terdapat di dalamnya.

a. Nilai Ekonomi Flora

Adapun nilai ekonomi flora yang ada di Hutan Mangrove Munjang Desa Kurau Barat disajikan pada Tabel 3.

Tabel 3. Nilai Ekonomi Flora Hutan Mangrove Munjang di Desa Kurau Barat Tahun 2019

\begin{tabular}{lcc}
\hline \multicolumn{1}{c}{ Jenis Flora } & $\begin{array}{c}\text { Luas Kawasan } \\
(\mathrm{Ha})\end{array}$ & $\begin{array}{c}\text { Nilai Ekonomi Flora } \\
(\mathrm{Rp})\end{array}$ \\
\hline Mangrove & 213 & 15.037 .827 .000 \\
\hline Sumber: Olahan &
\end{tabular}

Sumber: Olahan Data Primer dan Sekunder 2019

Jenis flora yang ada di Hutan Mangrove Munjang Desa Kurau Barat berdasarkan tabel diatas yaitu Perepat, Bogem, Perepat Lanang, Api-Api, Nyirih, Bakau Minyak, Lolaro, Bakau Merah, Biduri, Nipah, Waru Laut, Kelapa, Tanjung Merah, Tanjung Putih, Jeruju Hitam, Paku Laut, Api-Api Putih, Mengkudu, Pandan Tikar, dan Akasia. Nilai flora yang diperoleh yaitu sekitar Rp15.037.827.000, jenis flora yang memiliki potensi terbesar yaitu Bakau Merah sebesar Rp3.727.500.000, sedangkan jenis flora yang memiliki potensi paling sedikit yaitu Jeruju Hitam sebesar Rp26.652.000. sebenarnya nilai ekonomi flora yang ada di kawasan Hutan Mangrove Munjang lebih tinggi dari nilai ekonomi flora tersebut, karena hanya 20 spesies mangrove yang terdeteksi jenis dan jumlahnya. Hal ini dikarena keterbatasan informasi sehingga yang dihitung hanya flora yang terdeteksi jenis dan jumlahnya saja.

b. Nilai Ekonomi Fauna

Metode yang digunakan untuk mengidentifikasi fauna berupa metode jalur (strip transect) serta pengamatan tidak langsung diterapkan untuk jenis-jenis satwa yang sulit dijumpai secara langsung seperti jejak kaki, bulu, feses (kotoran), sarang dan jejak-jejak lainnya yang dapat dijadikan dalam pengumpulan data dan jumlah individu satwa. Panjang jalur yang digunakan yaitu 1 sampai dengan $2 \mathrm{~km}$. Data dikumpulkan berdasarkan pada perjumpaan langsung dengan satwa yang berada pada jalur pengamatan (Suhandar, 2016).

Berdasarkan hasil inventarisasi yang ditemukan maka dapat dihitung nilai ekonomi fauna hutan mangrove yang dimana harga setiap fauna menggunakan harga pasar umum yang berlaku. Nilai ekonomi fauna Hutan Mangrove Munjang Desa Kurau Barat secara keseluruhan dapat dilihat pada Tabel 4. 
Tabel 4. Nilai Ekonomi Fauna Tahun 2019

\begin{tabular}{lcc}
\hline \multicolumn{1}{c}{ Jenis Fauna } & $\begin{array}{c}\text { Luas Kawasan } \\
(\mathrm{Ha})\end{array}$ & $\begin{array}{c}\text { Nilai Ekonomi } \\
\text { Fauna (Rp) }\end{array}$ \\
\hline Reptil & 213 & 886.080 .000 \\
Aves & 213 & 3.525 .150 .000 \\
Mamalia & 213 & 2.875 .500 .000 \\
\hline \multicolumn{1}{c}{ Jumlah } & & 7.286 .730 .000 \\
\hline
\end{tabular}

Sumber: Olahan Data Primer dan Sekunder 2019

Berdasarkan Tabel 4 di atas, jenis fauna yang ada di Hutan Mangrove Munjang terdiri dari tiga kelas antara lain reptile (Ular Sanca Batik, Ular Cincin Emas, Kadal, Bengkarung, dan Biawak), mamalia (Lutung Kelabu, Bajing Kelapa, Monyet Ekor Panjang, Bajing Kerdil, dan Beruk), serta aves (Paok Bakau, Pekaka Emas, Sikatan Bakau, Caladi Tilik, Trinil Pantai, Cekakak Merah, Madu Bakau, Gajahan Penggala, Kancilan Bakau, Udang Punggung Merah, Elang Hitam, dan Ayam Hutan Merah) dengan nilai ekonomi sebesar Rp7.286.730.000.

c. Nilai Ekonomi Penyerapan Karbon

Objek wisata Hutan Mangrove Munjang yang terletak di Desa Kurau Barat, Kecamatan Koba, Kabupaten Bangka Tengah memiliki luas 213 hektar. Kawasan hutan mangrove dapat dikatakan merupakan wilayah berupa hutan primer yaitu hutan alam yang masih utuh yang belum mengalami gangguan alam maupun manusia. Nilai ekonomi penyerapan karbon hutan mangrove dengan penentuan nilai karbon yang digunakan pendekatan harga pasar karbon internasional dengan asumsi:

- 1 ha hutan primer menyimpan 283 ton karbon (Brown dan Peaece, 1994) dalam (Karmila, 2015)

- Nilai karbon adalah US\$ 5 per ton (asumsi US\$1= Rp 10.000, perubahan akan harga dollar di rupiahkan, maka dollar dihitung dengan harga Rp14.138,40 pada 10 Juli 2019.

Tabel 5. Perhitungan nilai karbon Tahun 2019

\begin{tabular}{cccc}
\hline $\begin{array}{c}\text { Luas } \\
(\mathrm{Ha})\end{array}$ & $\begin{array}{c}\text { Kemapuan } \\
\text { Serapan } \\
\text { (ton/ha) }\end{array}$ & $\begin{array}{c}\text { Harga Karbon/ha US\$ } \\
5 \times \mathrm{Rp} 14.138,40\end{array}$ & $\begin{array}{c}\text { Nilai Penyerapan } \\
\text { Karbon (Rp) }\end{array}$ \\
\hline 213 & 283 & Rp70.692,00 & 4.261 .243 .068 \\
\hline
\end{tabular}

Sumber: Olahan Data Primer dan Sekunder 2019

Berdasarkan Tabel 5, nilai penyerapan karbon yang diberikan objek wisata Hutan Mangrove Munjang Desa Kurau Barat yaitu sebesar Rp4.261.243.068. Perdagangan karbon ini membuat peluang menjual hutan tanpa menebang pohon, sehingga pembangunan yang berkelanjutan dapat terwujud. Dengan nilai serapan karbon tersebut, maka nilai serapan karbon di kawasan Hutan Mangrove Munjang masih bisa ditingkatkan dengan cara menjaga kelestarian hutan supaya tidak rusak. 
1. Nilai Ekonomi Total Hutan Mangrove Munjang

Nilai ekonomi total Hutan Mangrove Munjang tiap tahun adalah penjumlahan dari beberapa nilai ekonomi baik nilai manfaat langsung maupun manfaat yang tidak langsung. Perincian total nilai ekonomi Hutan Mangrove Munjang dapat dijelaskan pada Tabel 6 sebagai berikut.

Tabel 6. Total Nilai Ekonomi Hutan Mangrove Munjang Tahun 2019

\begin{tabular}{clc}
\hline No & Nilai Ekonomi & Total Nilai Ekonomi (Rp) \\
\hline 1 & Flora & 15.037 .827 .000 \\
2 & Fauna & 7.286 .730 .000 \\
3 & Serapan Karbon & 4.261 .243 .068 \\
4 & Biaya Perjalanan & 1.706 .760 .900 \\
\hline & Total & 28.292 .560 .968
\end{tabular}

Sumber: Olahan Data Primer dan Sekunder 2019

Nilai ekonomi total Hutan Mangrove Munjang yang luasnya sekitar $213 \mathrm{Ha}$ adalah sebesar Rp28.292.560.968 per tahunnya. Nilai ekonomi total ini diperoleh dari hasil penjumlahan dari nilai keanekaragaman hayati berupa nilai flora sebesar Rp15.037.827.000, nilai fauna sebesar Rp7.286.730.000, nilai serapan karbon sebesar Rp4.261.243.068, serta nilai biaya perjalanannya yaitu sebesar Rp1.706.760.900.

Hasil penelitian ini menunjukkan bahwa Hutan Mangrove Munjang memberi manfaat yang relatif tinggi bagi masyarakat baik ditingkat lokal, regional, nasional maupun global. Dari seluruh nilai ekonomi yaitu nilai flora, fauna, serapan karbon, serta biaya perjalanan, penyumbang terbesar terhadap nilai ekonomi Hutan Mangrove Munjang adalah nilai ekonomi flora dan faunanya. Sehingga dapat disimpulkan keberadaan Hutan Mangrove Munjang itu sangat penting karena adanya hutan tersebut maka keberadaan flora dan faunanya dapat terjaga dengan baik dan juga keberadaan Hutan Mangrove Munjang dapat membantu mengurangi emisi karbondioksida yang ada. Hal ini sejalan dengan penelitian Deshita (2015), hasil penelitian valuasi ekonomi menunjukkan bahwa kawasan hutan mangrove Desa Tiwoho mempunyai nilai manfaat yang cukup besar yang dapat menunjang perekonomian masyarakat yaitu Rp2.316.961.823 per tahun. Dengan demikian masyarakat bersama pemerintah diharapkan agar dapat bahu membahu untuk tetap menjaga dan melestarikan keberadaan hutan mangrove dengan menerapkan pengelolaan pemanfaatan yang lestari dan berkelanjutan.

\section{KESIMPULAN DAN SARAN}

\section{Simpulan}

Secara keseluruhan nilai ekonomi total objek wisata Hutan Mangrove Munjang yang luasnya 213 hektar adalah sebesar Rp28.292.560.968 per tahunnya. Nilai ekonomi total ini diperoleh dari hasil penjumlahan dari nilai keanekaragaman hayati berupa nilai flora sebesar Rp15.037.827.000, nilai fauna sebesar Rp7.286.730.000, nilai serapan karbondioksida sebesar Rp4.261.243.068, serta nilai biaya perjalanan (travel cost) yaitu sebesar Rp1.706.760.900. 


\section{Saran}

Saran yang dapat peneliti sampaikan adalah:

a. Bagi pengelola

Meningkatkan sarana prasarana, sehingga pengunjung merasa lebih nyaman ketika berkunjung ke objek wisata Hutan Mangrove. Perlu dilakukan pengawasan kepada masyarakat maupun pengunjung kawasan mangrove secara berkesinambungan agar hutan mangrove bisa terus terpelihara dan tidak tercemar. b. Bagi masyarakat

Masyarakat diharapkan untuk ikut menjaga dan merawat ekosistem mangrove munjang agar tetap lestari.

c. Bagi pemerintah

Pemerintah harus membuat suatu tata hukum dan menindak berbagai kegiatan yang merusak ekosistem hutan mangrove.

\section{DAFTAR PUSTAKA}

Aco, Andi Wahdiat. 2015. Valuasi Ekonomi Hutan Mangrove di Pesisir Pelabuhan Untia, Kecamatan Biringkanaya, Kota Makassar. Skripsi. Universitas Hasanuddin.

Badan Pusat Statistik. 2017. Bangka Tengah Dalam Angka. Proyeksi Penduduk Provinsi Kepulauan Bangka Belitung 2015-2025.

Deshita, W.K. 2015. Valuasi Ekonomi Hutan Mangrovedi Desa Tiwoho Kecamatan Wori Minahasa Utara. Jurnal Cocos. Vol. 6 No. 8.

Karmila, 2015. Valuasi Ekonomi Hutan Gunung Menumbing di Kecamatan Munok Kabupaten Bangka Barat. Skripsi. Univertsitas Bangka Belitung.

Kordi, M.G.H. 2012. Ekosistem Mangrove, Fungsi, Potensi dan Pengelolaan. Jakarta: Rineka Cipta.

Noya, D. 2012. Konsep Valuasi Ekonomi Sumberdaya Alam. Diakses Dari http://bungdanon.blogspot.co.id/2012/11/konsep-valuasi-ekonomisumberdaya-alam.html pada tanggal 12 Juli 2019.

Prasetiyo, D. E. 2013. Struktur Komunitas Mangrove dan Kepiting (Ocypodisae dan Grapsidae), Serta Pendugaan Karbon Tersimpan Pada Komunitas Mangrove di Kabupaten Raja Ampat. Skripsi. Universitas Jenderal Sudirman. Purwokerto.

Setiawan, M.A. 2017. Valuasi Ekonomi Objek Wisata Pantai Tongaci dengan Pendekatan Biaya Perjalanan (Travel Cost) di Kabupaten Bangka. Skripsi. Universitas Bangka Belitung.

Siaran Pers Kementerian Lingkungan Hidup dan Kehutanan. http://ppid.menlhk.go.id/siaran_pers/browse/561

Sugiyono. 2009. Metode Penelitian Kuantitatif, Kualitatif dan R\&D. Bandung: Alfabeta.

Suhandar, Arie. 2016. Valuasi Ekonomi Sumber Daya Hutan Pelawan di Desa Namang Kabupaten Bangka Tengah. Universitas Bangka Belitung. 
Susilowati. 2009. Valuasi Ekonomi Dengan Menggunakan Pendekatan Travel Cost Method. Skripsi Mahasiswa Departement Ekonomi dan Lingkungan, Fakultas Ekonomi dan Manajemen, Institut Pertanian Bogor.

Umar, Husein. 2011. Metode Penelitian untuk Skripsi dan Tesis Bisnis. Jakarta. PT Rajagrafaindo Persada. 